\title{
The neurodynamical basis of multi-item working memory capacity: sequential vs simultaneous stimulation paradigms
}

\author{
Marta Balagué $e^{1,2^{*}}$, Laura Dempere-Marco ${ }^{2}$ \\ From 24th Annual Computational Neuroscience Meeting: CNS*2015 \\ Prague, Czech Republic. 18-23 July 2015
}

When investigating multi-item WM, and in contrast to single item experiments, a decision must be made regarding a key aspect of the stimulation protocol: how the memory set is presented to the subject simultaneously or sequentially. It is worth noting that most studies investigating multi-item WM do not address this issue and focus either in simultaneous stimulation protocols (e.g. $[1,2])$ or in sequential stimulation protocols (e.g. [3]) without confronting the two situations. This is nevertheless an aspect which provides a benchmark to probe and compare the different theories regarding how resources are allocated among the different items of a memory set $[4,5]$. In this study, we explore a biophysically-realistic attractor model of visual working memory (VWM) endowed with synaptic facilitation and investigate what are the effects of varying the dynamics of the facilitation process. We find that: 1) it is possible to reproduce experimentally observed effects such as the recency effect in sequential stimulation protocols (i.e. items presented in the final positions of a sequence are more likely to be retained in WM), and 2) WM capacity is boosted in both sequential and stimulation protocols when endowing the attractor network with synaptic facilitation.

\section{Conclusions}

In agreement with our previous results [2], synaptic facilitation boosts the WM capacity limit by effectively increasing the synaptic strengths just for those pools to which a cue is applied, and then maintaining the synaptic facilitation by the continuing neuronal firing in only

\footnotetext{
* Correspondence: laura.dempere@upf.edu

'Moisès Broggi Hospital, Consorci Sanitari Integral, Sant Joan Despí, 08970, Spain

Full list of author information is available at the end of the article
}

these pools when the cue is removed. In this study, the time constant $\tau_{\mathrm{F}}$ of the synaptic facilitation process has been found to play an important role in modulating this effect with large $\tau_{\mathrm{F}}$ values leading to larger capacity limits in both sequential and simultaneous stimulation protocols. However, too large $\tau_{\mathrm{F}}$ values lead to neuronal dynamics which are not compatible with the recency effect, thus constraining the range of values that $\tau_{\mathrm{F}}$ may take.

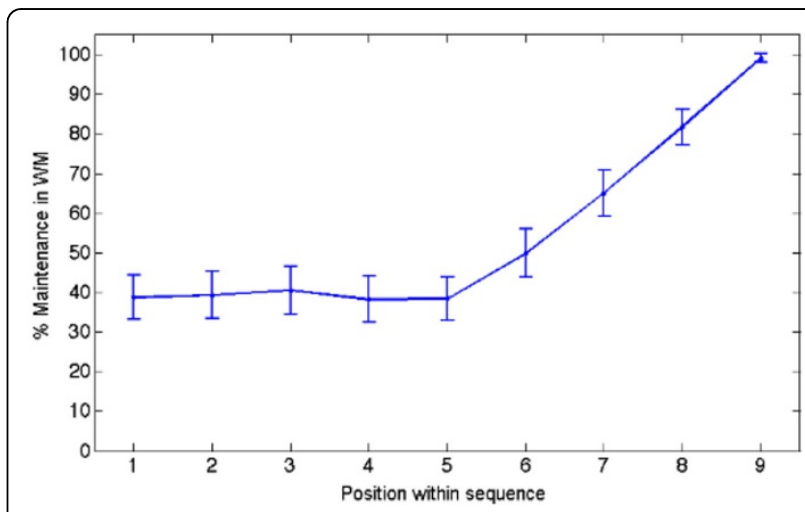

Figure 1 Maintenance of an item in WM memory as a function of its position within a sequence. The results are derived from computational simulations (100 blocks of 100 trials) of a delayed match-to-sample task (same stimulation protocol as in [3] and test item assimilated to a delayed match-to-sample task) with 9 selective neural assemblies sequentially stimulated. Maintenance in WM is estimated by assuming that an item is held in memory when its associated selective pool shows a mean persistent activity $v \geq 30 \mathrm{~Hz}$ during a period of $500 \mathrm{~ms} 2 \mathrm{~s}$ after the end of the last stimulation. The network parameters can be found in [2] and $\tau_{\mathrm{F}}=750 \mathrm{~ms}$ in this example. 


\section{Acknowledgements}

The authors acknowledge funding from the research project TIN2013-40630-

$\mathrm{R}$ (Spanish Ministry of Economy and Competitiveness)

\section{Authors' details}

'Moisès Broggi Hospital, Consorci Sanitari Integral, Sant Joan Despí, 08970, Spain. ${ }^{2}$ Department of Information and Communication Technologies,

Universitat Pompeu Fabra, Barcelona, 08018, Spain.

Published: 18 December 2015

\section{References}

1. Dempere-Marco L, Melcher DP, Deco G: Effective Visual Working Memory Capacity: An Emergent Effect from the Neural Dynamics in an Attractor Network. PLoS One 2012, 7(8):e42719.

2. Rolls ET, Dempere-Marco L, Deco G: Holding Multiple Items in Short Term Memory: A Neural Mechanism. PLoS One 2013, 8(4):e61078.

3. Amit D, Bernacchia A, Yakovlev V: Multiple-object working memory - a model for behavioral performance. Cereb Cortex 2003, 3:435-443.

4. Bays $P$, Husain M: Dynamic shifts of limited working memory resources in human vision. Science 2008, 321:851-854.

5. Zhang W, Luck S: Discrete fixed-resolution representations in visual working memory. Nature 2008, 453:233-235.

doi:10.1186/1471-2202-16-S1-P58

Cite this article as: Balagué and Dempere-Marco: The neurodynamical basis of multi-item working memory capacity: sequential vs simultaneous stimulation paradigms. BMC Neuroscience 2015 16(Suppl 1): P58.

\section{Submit your next manuscript to BioMed Central} and take full advantage of:

- Convenient online submission

- Thorough peer review

- No space constraints or color figure charges

- Immediate publication on acceptance

- Inclusion in PubMed, CAS, Scopus and Google Scholar

- Research which is freely available for redistribution

Submit your manuscript at www.biomedcentral.com/submit 